\title{
La lectura popular y comunitaria de la Biblia como didáctica de la Fe en contextos latinoamericanos
}

\author{
Fidel Mauricio Ramírez**
}

Recibido: 2 de marzo 2013 • Aprobado: 2 de mayo 2013

\section{Resumen}

El presente artículo aborda el tema de la Lectura Popular y Comunitaria de la Biblia (LPCB) como didáctica de la Fe en contexto Latinoamericano. Se expone el método de la LPCB y el aporte que éste hace en el proceso de encuentro entre un pueblo; que experimenta distintas formas de exclusión, y el mensaje que Dios tiene para ellos en su situación.

Palabras claves: lectura popular y comunitaria de la Biblia (LPCB), didáctica de la Fe, exclusión, comunidades eclesiales de base.

\section{Popular and community Bible reading as didactic of faith in Latin American contexts}

\begin{abstract}
This article approaches the subject of Popular and Community Bible Reading (LPCB in Spanish) as a didactic of faith in Latin American context. It presents the LPCB method and

* Texto de reflexión

** Doctorando en Educación de la Universidad Santo Tomás, Magister en Educación de la Universidad Santo Tomás; Licenciado en Teología de la Pontificia Universidad Javeriana. Actualmente docente de la Facultad de Teología de la Universidad Santo Tomas y Docente del área de Filosofía en la Secretaría Distrital de Educación. E-mail: fidelramirez@usantotmas.edu.co.
\end{abstract}


the contribution it makes in the process of encounter between people that experience different ways of exclusion and the message God has for them in their situation.

Keywords: Popular and community Bible reading (LPCB), didactic of Faith, exclusion, basic ecclesial communities.

Para este número de la revista Albertus Magnus, dedicado a la Pedagogía y la Teología en contexto latinoamericano, se presenta este artículo, producto de la reflexión llevada a cabo en el marco del Seminario de Teología Pastoral del programa de Teología de la Universidad Santo Tomas, sede Bogotá.

Aquí se abordan cuestiones del método de la Lectura Popular y Comunitaria de la Biblia y se expone cómo esta práctica, llevada a cabo por Comunidades Eclesiales de Base y pequeños grupos, conduce a las personas a un encuentro con Dios y al descubrimiento el mensaje que Él tiene para ellos en sus situaciones concretas. En tal sentido, se considera que a través de la LPCB hay un aprendizaje de la Fe y por ello se dice que la LPCB es una didáctica de la misma.

El esquema a seguir es el siguiente: primero se hará un acercamiento a la lectura LPCB como didáctica de la Fe y luego se presentará los elementos propios de la metodología. Es importante señalar que el tema es muy amplio y que por las características del mismo no se encuentra sistematizado el proceso; por tanto, los referentes teóricos pueden resultar escasos, pero no por ello poco profundos. Muchos de los documentos producidos al respecto circulan anónimamente en medio de los grupos y comunidades que van recogiendo su experiencia sin rigor académico; quizás los únicos que han hecho ese proceso son Pablo Richard y Carlos Mester y por esa razón son ellos quienes se constituyen como principales referentes.

\section{La LPCB como didáctica de la Fe}

Etimológicamente, el término didáctica procede del griego: didaktiké, didaskein, didaskalia, didaktikos, didasko (didaktike, didaskein, didaskalia, didaktikos, didasko). Estos términos tienen en común su relación con el verbo enseñar, instruir, exponer con claridad. Desde su origen, en la antigüedad clásica griega, el sustantivo didáctica ha sido el nombre de un género literario: aquel que pretende enseñar, formar al lector.

Quienes escriben obras de didáctica aportan nuevos elementos a su definición, pero en esencia permanece la misma coincidencia en torno al acto de 
enseñar. Estebaranz (1994, 41) Sáenz Barrio (1992, p.14) y Ruiz (1996, p.25), presentan un completo análisis de las definiciones de muchos autores con el fin de hallar los elementos comunes a todas ellas. Entre éstas podemos encontrar la de Fernández Huerta (1974, p.27), quien apunta a que la "Didáctica tiene por objeto las decisiones normativas que llevan al aprendizaje gracias a la ayuda de los métodos de enseñanza". Por su parte, Escudero (1981) insiste en el proceso de enseñanza-aprendizaje: “Ciencia que tiene por objeto la organización y orientación de situaciones de enseñanza-aprendizaje de carácter instructivo, tendentes a la formación del individuo en estrecha dependencia de su educación integral" (p.117).

En tal sentido, se puede decir que la Didáctica es la ciencia que estudia e interviene en el proceso de enseñanza-aprendizaje con el fin de conseguir la formación intelectual del educando.

Por su parte, cuando hablamos de Fe, nos vamos a referir en el sentido que lo hace el Catecismo de la Iglesia Católica, que dice que la Fe es la adhesión personal del hombre a Dios que nos ha creado a su imagen y semejanza y, además, ha querido revelarse, darse a conocer. Dios «habla a los hombres como amigo, movido por su gran amor y mora con ellos para invitarlos a la comunión consigo y recibirlos en su compañía». La respuesta adecuada a esta invitación es la Fe.

Por lo anterior, se dice que la Lectura Popular y Comunitaria de la Biblia (LPCB) es una didáctica de la Fe, pues es una práctica existencial a través de la cual una comunidad busca encontrar el mensaje que Dios tiene para ellos en su situación actual. A través de la lectura bíblica, realizada generalmente en Comunidades Eclesiales de Base, inserta en medios populares en América Latina, se busca rescatar el sentido histórico y espiritual de la Biblia (Richard, 1988). El punto de partida no es simplemente el texto de la Biblia, se hace necesario que ese texto esté en relación con la vida de cada uno de los lectores y lectoras, tal y como lo señala Mester (2005).

Esto significa que, en el fondo, el criterio básico o la fuente de todo no es la Biblia ni el estudio de la Biblia, sino la experiencia que hoy tenemos del Dios y de la vida, y yo no estoy solo sino yo estoy dentro de la comunidad y dentro de la humanidad, y en comunión con ella, y de ella recibo mi identidad y sensibilidad. O mejor, el criterio básico está en esta interacción del texto del pasado con nosotros que hoy leemos el texto. (p.20)

Cuando una comunidad lee el texto bíblico no lo hace con el deseo de conocer o cultivar una curiosidad académica. Cuando una comunidad lee el texto lo 
hace para encontrar en él respuestas a su situación actual. En el caso concreto de comunidades empobrecidas y marginadas, lo hacen para buscar una esperanza que aliente y guíe su lucha por alcanzar la liberación de estructuras de miseria y explotación. Desde esta perspectiva, la teología de la liberación ha demostrado que la Biblia, si es leída con ojos nuevos, transmite un mensaje liberador para todos.

Puede decirse entonces que el texto de la Biblia se convierte en una mediación que integra la imaginación, el lenguaje y el símbolo a través de la cual se puede desarrollar la sensibilidad los lectores ante la Palabra liberadora de Dios que es asumida como proyecto e ideal.

Con la LPCB, el pueblo va descubriendo que la Biblia les pertenece y que son sujetos válidos para su interpretación. Las comunidades van sintiéndose identificadas con el pueblo de Israel, con las explotaciones que viven, con sus búsquedas por construir una nueva sociedad, pero a la vez también se identifican con los fracasos del pueblo. Podría decirse que se va generando un efecto reflejo, en el que la comunidad lectora se va descubriendo en el texto que lee. Por ejemplo, cuando se leyó el libro de las Lamentaciones con una comunidad de desplazados por la violencia, muchos de ellos se sintieron identificados con el profeta, e incluso se atrevieron a crear sus propias quejas. Sin embargo, esta manera de leer la Biblia no es nueva, así era como se interpretaba la Biblia en tiempos de Jesús y en los primeros siglos ${ }^{1}$.

Por el hecho de que alguien use las palabras de la Biblia para transmitir una experiencia que vivió, él está diciendo que su experiencia se sitúa en un río que viene desde los tiempos de la Biblia. O mejor, él expresa el deseo de beber del mismo pozo en que bebieron las personal del tiempo de la Biblia, y de sentirse animado por el mismo Espíritu que animaba a ellas en aquel tiempo. (Mester, 2005, p.21)

Pero descubrirse en el texto no es suficiente. Para que exista una verdadera práctica de Lectura Popular y Comunitaria de la Biblia, es necesario que a la identificación con el texto siga una toma de postura y un compromiso personal

1 Según Carlos Mester, esta antigua tradición reaparece hoy, sin etiqueta, en la manera como el pueblo de las comunidades usa la Biblia. Lo que caracteriza la lectura cristiana de la Biblia son tres cosas: familiaridad, libertad y fidelidad. (Cf. Mester, C. (2005). Lo que me sale del Corazón sobre la fuente y el rumbo de la interpretación de la Biblia. RIBLA, $\mathrm{N}^{\circ} 50$. Quito, Ecuador. 18-21. 
y comunitario por la transformación de las realidades. Desde esta perspectiva, toda practica de Lectura Popular y Comunitaria de la Biblia debe ser liberadora.

En el campo del sentido común, lo primero que aflora es el despliegue de la sensibilidad, de los sentimientos, emociones, afectos, etc. (...). En segundo lugar, existen las transposiciones que debe afrontar el pensamiento teológico al enfrentarse con la mente y el corazón de todas las culturas y clases. En tercer lugar, está el reto de las adaptaciones que hay que hacer según las urgencias de los tiempos, lugares, personas, etc. ${ }^{2}$

En la Iglesia Católica se ha reservado el privilegio de la interpretación bíblica al Magisterio. Este hecho posee una dinámica estructural que conduce a la dominación de las conciencias, generando durante mucho tiempo el predominio de estructuras de poder. Las interpretaciones tradicionales de la Biblia, hechas en su gran mayoría por hombres; miembros de una élite, no pueden servir a la liberación de los oprimidos, sino que más bien, en muchos casos, ha servido de manera de legitimación de la opresión. Por esta razón, para la LPCB la comunidad se constituye en el sujeto intérprete de la Palabra de Dios ${ }^{3}$.

En la Lectura Popular de la Biblia, nuevo espacio para la Palabra de Dios, hemos construido un nuevo sujeto intérprete de la Palabra de Dios. Hasta ahora solo se reconocía como sujeto al exégeta (al especialista en Biblia) o a la autoridad jerárquica, tanto magisterial como litúrgica. Estos sujetos son necesarios y legítimos, pero insuficientes, por eso surge un nuevo sujeto intérprete de la Palabra de Dios en la Lectura Popular de la Biblia. Este nuevo sujeto está naciendo en toda la Iglesia, pero fundamentalmente en las Comunidades Eclesiales de Base y otras comunidades similares. Este nuevo sujeto es todo bautizado capaz de leer e interpretar la Biblia, no en forma individual, sino en comunidad y con la ayuda (no tutoría) de las ciencias bíblicas y de las autoridades de la Iglesia. Este nuevo sujeto intérprete de la Palabra de Dios tiene

2 Lonergan, B. (s.f). Método en Teología, op.cit. p. 131-132. Citado: Monguí, J.R. (s.f). Humanismo I: desarrollo de la sensibilidad, Informe Maestro I. Maestría en Educación, Universidad Santo Tomás, p. 32.

3 En la tradición cristiana el sujeto que interpreta la Biblia no es un individuo aislado, sino fundamentalmente un sujeto que vive en comunidad (...) Es la exigencia de la comunidad lo que da solidez, continuidad y dimensión social a la Lectura de la Biblia. (Cf. Richard, P. (2004). Fuerza ética y espiritual de la Teología de la Liberación. San José de Costa Rica: DEI, p. 117. 
las siguientes cualidades: autoridad, legitimidad, autonomía, libertad y creatividad. (Richard, 1988, p.34)

Las mujeres, los afrodescendientes, los campesinos, las minorías sexuales, cuando se reúnen para leer la Biblia aportan elementos nuevos en el proceso hermenéutico. Estos nuevos sujetos, que emergen lentamente, entran en contradicción con el sujeto histórico dominante y opresor. Aparece una ruptura entre la manera tradicional en la que han sido leído los textos en el terreno político, en el terreno económico, cultural e ideológico y van surgiendo nuevas preguntas que dan origen a una nueva conciencia.

Richard (1988) plantea que la reforma no la hacen los jerarcas, los teólogos o los exégetas, sino el Pueblo de Dios, organizado en comunidades, que lee e interpreta las sagradas escrituras. Porque cuando las comunidades leen la Biblia van descubriendo que la situación de deshumanización, explotación y opresión que viven no es la verdadera vocación a la que están llamados. Su vocación es la de la humanización y ésta debe ser conquistada a través de una praxis que lo libere de su condición actual.

La LPCB es una práctica de liberación que le permite al oprimido descubrirse y conquistarse, en forma reflexiva, como sujeto de su propio destino histórico. Es una práctica a través de la cual las comunidades oprimidas empiezan a ir develando el mundo de la opresión y se van comprometiendo, en la praxis, con su transformación. Es una práctica que se constituye en didáctica de la Fe, en la medida que cada hombre y mujer que leen la Biblia, va teniendo una adhesión personal (y comunitaria) a Dios y va descubriendo como Éste se revela en la situación concreta que está viviendo.

\section{Método de la LPCB}

El método de la LPCB es fundamentalmente de análisis de la realidad, que, a su vez, se traduce en una espiritualidad de la liberación: no puede existir una verdadera espiritualidad si ésta está desencarnada de la realidad humana.

En la LPCB no se confunde lo espiritual y la realidad, ni se absorben, ni se contraponen. Lo que hace es distinguir su unidad bajo el argumento de que el ser humano descubre a Dios a través de la revelación histórica; Dios se manifiesta en la lucha del pueblo por lograr su libertad.

La Comunidad Cristiana escucha la Palabra de Dios en un contexto de oración y de espiritualidad. Biblia y espiritualidad van juntas. Pero

\section{Universidad Santo Tomás, Facultad de Teología}


falta el tercer elemento constitutivo de la Comunidad: la Solidaridad. Biblia, Espiritualidad y Solidaridad forman por lo tanto una unidad. Una comunidad no puede dedicarse sólo a la Biblia, dejando de lado la Espiritualidad y la Solidaridad (sería una comunidad fundamentalista). Tampoco se puede vivir únicamente la Espiritualidad sin Biblia y Solidaridad (sería una comunidad espiritualista). Finalmente, no es cristiana una comunidad que sólo vive la Solidaridad, sin Espiritualidad y Biblia. Dios mismo es Amor, Palabra y Espíritu (AGAPE-LOGOS-PNEUMA). (Richard, 2004, p.115)

El método de la LPCB no busca hacer que el hombre conozca su posibilidad de ser libre, sino que aprenda a hacer efectiva su libertad y, haciéndola efectiva, la ejerza; que en este ejercicio de liberación vaya descubriendo la presencia de Dios actuando entre ellos. Esta práctica de liberación acepta la sugestión de la antropología que va por la línea de la integración entre el pensar y el vivir. De tal manera que las comunidades que se ejercitan en la metodología de la LPCB, a medida que van descubriendo las explotaciones de las que son víctimas, deben ir consolidando un proyecto alternativo de liberación.

El método de LPCB esta basado en la práctica de la liberación, y por esta razón, está sometido constantemente al cambio, a la evolución dinámica y reformulación. Si reconocemos que el centro de dicha práctica es el sujeto comunitario, y que este sujeto está en constante diálogo con el mundo, es obvio que el método tendrá que seguir su ritmo de dinamicidad y desarrollo como una constante reformulación.

\section{El sujeto comunitario como intérprete de la Palabra de Dios}

El método de la LPCB está enraizado sobre la concepción del ser humano como sujeto comunitario. El sujeto-individuo se define en el "pienso, luego existo" (Descartes). Por el contrario, el sujeto-comunidad se define en el "yo soy si también eres tú" (Desmond Tutu). El sujeto-individuo se afirma en competencia con el otro, en la derrota y eliminación del otro. Es el yo que triunfa en la competencia y que es capaz de utilizar al otro como medio para conseguir sus objetivos. El sujeto-comunidad, por el contrario, busca al otro como condición de su propia existencia como sujeto.

El sujeto comunitarios de la LPCB es aquel que busca al otro para establecer una relación de reciprocidad, porque a través del otro se siente interpelado. Entiende que la muerte del otro es su propia muerte, es decir, que todo asesinato 
es en definitiva un suicidio. El sujeto comunitario es un ser en el mundo y con el mundo. Lo propio de este sujeto, es su capacidad de pensar con otros el mundo, de objetivarlo y transformarlo. En términos de Freire podríamos decir que el sujeto comunitarios de la LPCB es un sujeto conciente. "La conciencia es conciencia del mundo: el mundo y la conciencia, juntos, como conciencia del mundo, se constituyen dialécticamente en un mismo movimiento, en una misma historia. En otras palabras: objetivar el mundo es historizarlo, humanizarlo. Entonces, el mundo de la conciencia no es creación, sino elaboración humana. Ese mundo no se constituye en la contemplación sino en el trabajo"'(Richard, 2004, p.75).

\section{A manera de conclusión}

Probablemente esta metodología de la Lectura Popular y Comunitaria de la Biblia puede generar un poco de incomodidad, especialmente en el contexto teológico de la Iglesia Católica, donde la interpretación de la Biblia corresponde al Magisterio. Sin embargo, cuando se me invitó a participar de esta publicación, en el que se expondrían elementos de la reflexión teológica en el contexto de América Latina, no quise desaprovechar la oportunidad para compartir con ustedes esta metodología de Lectura Bíblica que se constituyó, y que aún hoy, se sigue constituyendo en una mediación en la relación de muchos cristianos con el mensaje liberador de Dios.

Definitivamente, la Lectura Popular y Comunitaria de la Biblia, es una metodología que ha generado grandes procesos de transformación social y se ha constituido en el fundamento de una construcción teológica, hecha por personas sencillas en busca de encontrar esperanza a sus realidades concretas, y en esa medida, son un aporte interesante a la reflexión teológica en general que se realiza en la academia. Como profesionales en Teología no podemos dar la espalda a las reflexiones hechas por las comunidades de Fe. Más bien, a partir de ellas, podemos tener un polo a tierra en nuestro ejercicio académico.

\section{Referencias}

Benedito, V. (1986). Aproximación a la Didáctica. Barcelona: PPU. (1987). Introducción a la Didáctica. Fundamentación teórica y diseño curricular. Barcelona: Barcanova.

Escudero, J.M. (1981). Modelos didácticos. Barcelona: Oikos-Tau. 
Estebaranz, A. (1994). Didáctica e innovación curricular. Sevilla: Publicaciones de la Universidad de Sevilla.

Fernández Huerta, J. (1974). Didáctica. Madrid: UNED.

Mester, C. (2005). Lo que me sale del Corazón sobre la fuente y el rumbo de la interpretación de la Biblia. RIBLA $N^{\circ} 50$. Quito, Ecuador.

Richard, P. (1988). Lectura popular de la Biblia en América latina, Hermenéutica de la liberación. RIBLA $N^{\circ} 1$. Quito, Ecuador,

Richard, P. (2004). Fuerza ética y espiritual de la Teología de la Liberación. San José de Costa Rica: DEI.

Ruiz, J.M. (1996). Teoría del currículum: diseño y desarrollo curricular. Madrid: Universitas.

Sáenz Barrio, O. dir. (1992). Didáctica general. Un enfoque curricular. Alcoy, España: Marfil.

Universidad Santo Tomás. (s.f). Campo de Formación Humanista. Informe Maestro I. Maestría en Educación. 